\title{
Correction to Size-resolved Identification, Characterization and Quantification of Primary Biological Organic Aerosol at a European Rural Site
}

Carlo Bozzetti, $^{\dagger}$ Kaspar R. Daellenbach, ${ }^{\dagger}$ Christoph Hueglin, ${ }^{\ddagger}$ Paola Fermo, ${ }^{\S}$ Jean Sciare, Anneliese Kasper-Giebl, ${ }^{\perp}$ Yinon Mazar, ${ }^{\#}$ Gülcin Abbaszade, ${ }^{\nabla}$ Mario El Kazzi, ${ }^{\text {, }}$ Raquel Gonzalez, ${ }^{\S}$ Timor Shuster-Meiseles, ${ }^{\#}$ Mira Flasch, ${ }^{\perp}$ Robert Wolf, ${ }^{\dagger}$ Adéla Křepelová, ${ }^{\dagger}$ Francesco Canonaco, ${ }^{\dagger}$ Jurgen Schnelle-Kreis, ${ }^{\nabla}$ Jay G. Slowik, ${ }^{\dagger}$ Ralf Zimmermann, ${ }^{\nabla,}{ }^{\prime}$ Yinon Rudich, ${ }^{\#}$ Urs Baltensperger, ${ }^{\dagger}$ Imad El Haddad, ${ }^{* \dagger}$ and André S. H. Prévôt* ${ }^{*}{ }^{\dagger}$

${ }^{\dagger}$ Laboratory of Atmospheric Chemistry, Paul Scherrer Institute, Villigen 5232, Switzerland

${ }^{\ddagger}$ Swiss Federal Laboratories for Materials Science and Technology, EMPA, Dübendorf 8600, Switzerland

${ }^{\S}$ Università degli Studi di Milano, Milano 20133, Italy

"Laboratoire des Sciences du Climat et de l'Environnement, LSCE, CNRS-CEA-UVSQ, Gif-sur-Yvette 91190, France

${ }^{\perp}$ Institute of Chemical Technologies and Analytics, Vienna University of Technology, Wien 1060, Austria

\#Department of Earth and Planetary Sciences, Weizmann Institute of Science, Rehovot 76100, Israel

${ }^{\nabla}$ Helmholtz Zentrum München, German Research Center for Environmental Health (GmbH), Joint Mass Spectrometry Centre, Cooperation Group Comprehensive Molecular Analytics, 85764 Neuherberg, Germany

${ }^{x}$ Electrochemistry Laboratory, Paul Scherrer Institute, Villigen 5232, Switzerland

Analytical Chemistry \& Joint Mass Spectrometry Centre, Institute of Chemistry, University of Rostock, 18051 Rostock, Germany

Environ. Sci. Technol. 2016, 50, 3425-3434; DOI: 10.1021/acs.est.5b05960.

$\sqrt{ }$ he authors regret that a calculation error occurred in the

1 determination of ambient cellulose concentrations from filter loadings in our article "Size-resolved Identification, Characterization and Quantification of Primary Biological Organic Aerosol at a European Rural Site". This resulted in cellulose concentrations that were biased high by a factor 2 . The correct summer average cellulose contribution to the coarse organic matter $\left(\mathrm{OM}_{\mathrm{COARSE}}\right)$ fraction was $24 \pm 12 \%$. The summer cellulose contribution to the water insoluble OM COARSE $_{\text {was }} 43 \%$ avg (pg. 3430). Cellulose together with WSOM represented 62\% of $\mathrm{OM}_{\text {COARSE }}$ (pg. 3430). The median WSPBOA:Cellulose ratio was 0.61 , first quartile 0.51 , third quartile 0.81 (SI, pg. S20, line 297). This error decreases the initial contribution of cellulose, but does not alter the conclusions of the original article. The Graphical TOC entry and Figure 1 were corrected as follows:

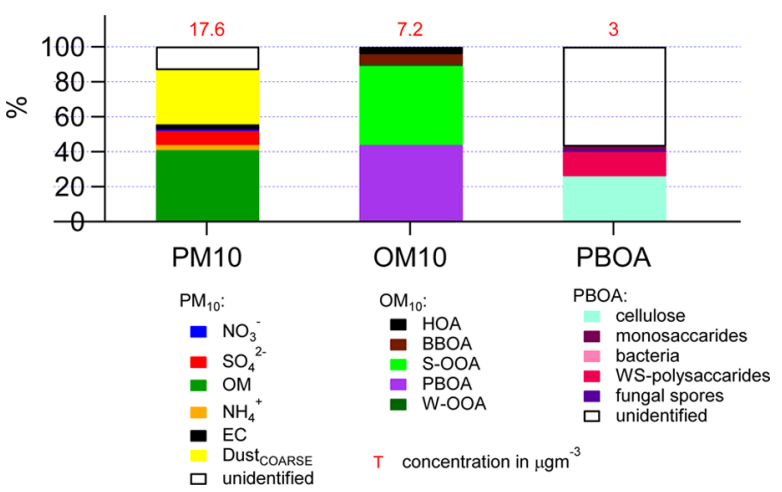



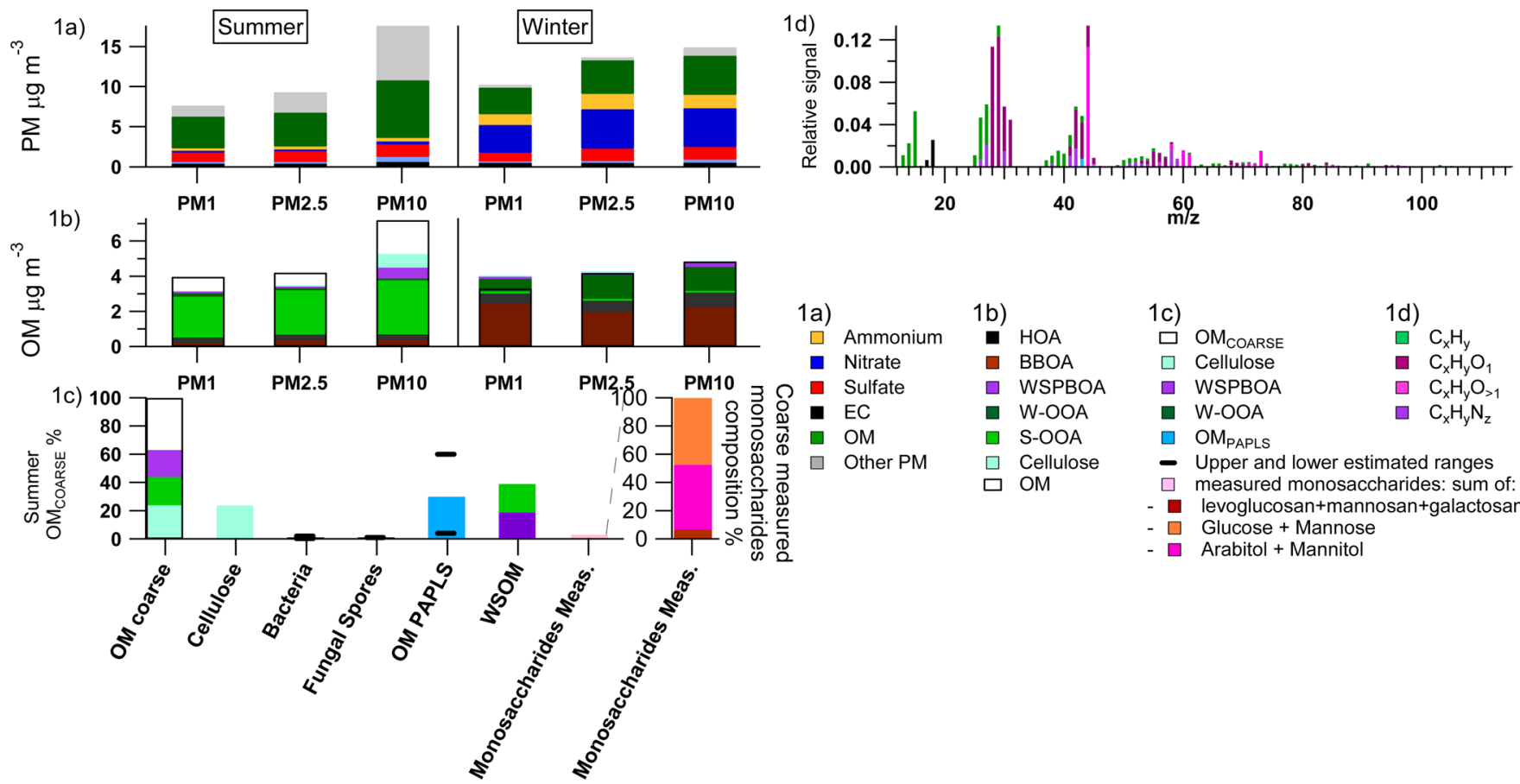
1b)
- $\mathrm{HOA}$
- BBOA
1c)
OM
$\square$ Cellulose
WSPBOA
WSPBOA
- W-OOA
S-OOA
$\square$ Cellulose
- W-OOA
$\square$ OMPAPLS
- Upper and lower estimated ranges
$\square$ measured monosaccharides: sum of
- levoglucosan+mannosan+galactosan
- Glucose + Mannose
- Arabitol + Mannitol

Figure 1. (1a) Seasonal PM chemical composition of the different size fractions. The $\mathrm{OM}_{i}$ estimate was calculated from $\mathrm{OC}_{i}$ measurements multiplied by the corresponding $\mathrm{OM} / \mathrm{OC}_{i}$ retrieved from offline-AMS HR analysis. (1b) Average seasonal aerosol sources contributions to OM in the different size fractions. White bars are consistent with our estimate of the water insoluble PBOA fractions (Figure S8). (1c) Summer OM $\mathrm{COARSE}_{\mathrm{C}}$ major components. (1d) WSPBOA high resolution AMS mass spectrum. 